\title{
Challenges of Macro-ethics: Bioethics and the Transformation of Knowledge Production
}

\author{
Hub Zwart
}

Received: 29 June 2007 / Accepted: 2 June 2008 / Published online: 29 August 2008

(C) The Author(s) 2008

\begin{abstract}
One interesting aspect of the Hwang-case has been the way in which this affair was assessed by academic journals such as Nature. Initially, Hwang's success was regarded as evidence for the detrimental effects of research ethics, slowing down the pace of research in Western countries. Eventually, however, Hwang's debacle was seen as evidence for the importance of ethics in the life sciences. Ironically, it was concluded that the West maintains its prominence in science (as a global endeavour) precisely because it has its ethics in place. Bioethics was now seen as an indispensable part of quality control. In this article, I will claim that the Hwang case rather reveals that there is no reason for complacency and that there are substantial challenges awaiting us. They have to do with major transformations in the way knowledge is produced and research in the life sciences is conducted (such as the increase in pace and scale, globalisation and the growing importance of ICT and bioinformation). These transformations call for a
\end{abstract}

An early version of this paper was presented at the 8th world conference on Bioethics. Beijing, China. August 62006

H. Zwart

Faculty of Science, Department of Philosophy and Science

Studies, Centre for Society and Genomics,

Radboud University Nijmegen,

Nijmegen, The Netherlands

H. Zwart $(\bowtie)$

P.O. Box 9010, 6500 GL Nijmegen, The Netherlands

e-mail: h.zwart@science.ru.nl different kind of bioethics. The focus must shift from duties of autonomous researchers concerning visible research subjects ("micro-ethics") to responsibilities of institutionalised research networks in managing and processing large amounts of bioinformation ("macro-ethics"). Concepts such as transparency, reliability and benefit-sharing will become more important than concepts such as informed consent. Basically, it is a resurgence of the tension between the Kantian and the Hegelian view of ethics. The contours of macro-ethics will be elaborated notably as it is emerging in bioethical debates over biobanking and genetic databanks.

Keywords Bioethics · Macro-ethics · Research ethics · Genomics $\cdot$ Bioinformation · Globalisation ·

Biobanking

\section{Introduction: Lessons from the Hwang Case}

On 12 March 2004 the South-Korean science celebrity Woo-Suk Hwang announced that his team had succeeded in cloning human stem cells. He pointed out that his research was carried out for therapeutic cloning only, not for reproductive cloning, and that the breakthrough was likely to have a major impact for the fight against degenerative disorders such as diabetes and Parkinson's disease. Moreover, he assured his readers of the ethical soundness of his research, stressing that it was done in compliance with 
ethical rules and standards. Notably, he stated that "before beginning any experiments we obtained approval for this study from the Institutional Review Board on Human Subjects" (Hwang et al. 2004, 1669). He also stressed that donors had donated oocytes and cumulus cells voluntarily, and that they had been "fully aware of the scope of our study and signed an informed consent form" (idem).

Soon, however, rumours began to emerge, notably concerning the manner in which the egg donors had been recruited (Nature 429, 490). It was questioned whether the ethical assessment by the Institutional Review Board had been sufficiently rigorous. In short, there was a growing concern over the lack of transparency surrounding Hwang's research. Eventually, it turned out that the basic research material (human egg cells) had been obtained from team members, raising serious concerns regarding health risks, gender issues and the voluntary nature of the donation. Even the reliability of the data themselves became an issue. In the end, Hwang admitted that the findings had been fabricated, and his papers were retracted (Kennedy 2006). His name became associated, not with a major breakthrough, but with a major (and highly visible) case of fraud.

One interesting aspect of the Hwang-case has been the way in which this affair was monitored and assessed by the academic research community in the West. It actually was a tale of two (highly competitive) top journals. Whereas Hwang himself published his original papers in Science, a train of editorials and comments on the Hwang case appeared in Nature. The latter journal obviously felt challenged by what was happening in South-Korea, as well as in Science. Initially, in the first series of comments, the Hwang case was seen as evidence that South-Korea had become a scientific "superpower". 1 Science was described in terms of a global competition between the West and the Far East. Apparently, "Asian tigers" were winning this science war, notably because of the detrimental influence of research ethics in the West. Western researchers were depicted as finding themselves in ethical trenches, as being "stranded" and tied up in a "stalemate" (such as the debate over

\footnotetext{
1 "Cloning success marks Asian nations as scientific tigers. The successful cloning of human embryos by a South Korean team has alerted Western researchers to the pace of scientific and technological progress in East Asia”. (Nature, 427, 664).
}

reproductive and/or therapeutic cloning, Nature 427, 664). Science in East Asia on the other hand was described in terms of a Blitz war, a massive attack on Western positions, ${ }^{2}$ fuelled by funding on an unprecedented scale, allowing South-Korea and other Asian nations (such as China, Japan and Vietnam) to emerge as the new frontiers of science (Nature 435, 26, 393). Western visitors were taken aback by the sheer scale of Hwang's research facilities (Nature 429, 13). In this global competition or "arms race" (Nature 438, 135), institutionalized ethics (committees, regulations, procedures), in combination with a science unfriendly "moral climate" (i.e. widespread distrust in science and technophobia) was seen as delaying and frustrating scientific progress in Western countries, while in East Asia scientific progress was apparently "encouraged" by a much more science-friendly atmosphere. Even Hwang himself attributed his success to a "supportive cultural environment, well-funded laboratories and legislation that permits cloning of human embryos for research". Willingness to donate egg cells by Korean donors was explained by him in terms of "cultural differences". He also praised the work ethic in his lab: "No Saturday, no Sunday and no holidays" (Nature 427, 664). Compared to the West, South-Korean science could profit from "national pride" and a great willingness to serve the common good (Nature 429, 14).

As the affair was heading for debacle, however, a dramatic reversal in the comments and editorials in Nature became apparent, notably with respect to the role and significance of research ethics. The question whether ethics constitutes an obstacle for research or rather a support, was suddenly addressed in a completely different manner. Life science ethics or bioethics now emerged as an indispensable monitoring tool, an important aspect of quality control. Tight regulations were now seen as a strength, rather than as a weakness. On 17 November 2005 it was said that the Hwang case showed that, in order to maintain public support, researchers needed to follow "strict ethics guidelines" (Nature 438, 257). Skeptics worldwide had to be persuaded that research in general and stem cell research in particular was being done

\footnotetext{
${ }^{2}$ The rhetoric of the arms race was also noticeable when Gerard Schatten from Pittsburgh University announced his decision to end collaborations with Hwang's team: Hwang had now lost one of his major "Western allies" (Nature 438, 262).
} 
ethically. If this failed, researchers would "find themselves on the defensive in proving that they are ready to stick to strict ethical codes" (idem). And on 12 January 2006 it was firmly stated that "sound ethics and good research practice go hand in hand" (Nature 439, 117). The West had won its competition, its fight for primacy in science (for the time being at least), precisely because its research ethics was less flexible and more robust. In other words, Nature editorials and comments were rediscovering the importance of ethics, of the ethico-legal infrastructure: "Research ethics matters immensely to the health of the scientific enterprise. Anyone who thinks differently should seek employment in another sphere" (Nature 439, 118). In countries such as China and South-Korea, it was argued, "mechanisms for supervising ethics and investigating misconduct are at relatively early stages of development" (117). The Western system of teaching students about ethics, "imperfect as it may be, is still more advanced than that of many other nations" (idem). Finally Gottweis and Triendl more or less summed it all up by stating that "good governance is crucial for research" (2006, 141). Although the absence of regulation might allow research to progress unimpeded, this is not always beneficial for research: regulatory oversight in the name of ethics adds an important layer to "the web of quality control in research" (143). The basic conviction embedded in these Nature comments can be summarised as follows: Western competitiveness resided in its ethical, rather than in its technological "superiority". The West had safeguarded its prominence precisely because it had its ethics in place.

The suggestion, that "we" (in the West) have our ethics in place, is questionable. To begin with, the framing of the Hwang case as an "Asian" problem is highly dubious. Although Gerard Schatten withdrew his participation, he did so when the case was already heading for debacle, while a Western institutional review board, at the University of Pittsburgh, had approved his participation. Moreover, the dubious claim made by Hwang concerning the willingness of Asian women to put the greater national good ahead of their own welfare must be seen as part of Hwang's rhetorical strategy while under siege and therefore viewed with skepticism.

In this article I will argue that, although ethics has indeed become an embedded dimension in the fabric of knowledge production in Western countries, there is no reason for complacency. Rather, the Hwang case is an indication that bioethics worldwide (in the West as well as in the East) is facing tremendous challenges. They arise from the ways in which contemporary research practices are actually evolving in terms of pace and scale. These transformations put pressures on our ethical infrastructures and the question is whether bioethics anywhere in the world is really "ready" for these developments. I will argue that in important respects, we are behind schedule. Basically, mainstream Western science ethics has developed on the basis of the idea that research is done by more or less autonomous individuals, able and willing to take responsibility for their own research, making their own decisions. In contemporary research practices, however, research is usually carried out by international and interdisciplinary teams, by large consortia or networks of more or less "anonymous" (rather than "autonomous") researchers. Some of the basic constituents of traditional bioethics may have become outdated by the way in which scientific research practices are actually developing. Although traditional concepts such as autonomy, responsibility and informed consent (IC) remain important no doubt, we have to address a number of relatively new and complicated issues on the macrolevel as well. On this level, the question is not whether or why informed consent (for instance) is important. Rather, the question is how such principles are to be institutionalised and maintained in a globalising and competitive environment.

Whereas the focus of micro-ethics basically is on the obligations of individual researchers vis-à-vis individual research subjects, macro-ethics rather addresses the issue of how moral practices are to be organised. The focus now shifts from issues such as autonomy and human rights to issues such as transparency and participation. This does not mean that "traditional" concepts such as informed consent (IC) become unimportant, but we increasingly need to address them from a different angle. In the context of an interaction between an individual researcher and an individual research subject, facing one another, the issue of IC will be addressed differently than when we are dealing with (electronic) interactions between large groups of anonymous individuals, separated from one another in space and time, in the context of genetic databanking for example. In the latter case, the concept of IC will not become irrelevant, of 
course, but will become part of a web of often novel and complicated questions.

It is possible and even useful, of course, to assess the Hwang case from the perspective of traditional science ethics or micro-ethics, as I will call it. Hwang is then seen as an autonomous researcher who in the end must be held responsible for what happened in his lab, and this is an important dimension no doubt. Such a perspective will highlight aspects such as Hwang's failure to treat the women who provided the eggs respectfully (not only by exerting implicit pressure on the consent of his junior research team members, but also by buying over half of the eggs he used from a Korean egg broker), as well as his untruthfulness concerning the numbers of eggs he used. Initially Hwang claimed that he had created eleven stem cell lines from just over two hundred eggs, while actually using 2,200 ova to produce precisely zero stem cell lines (Dickenson 2007). Yet, if we limit ourselves to such an approach, other aspects and issues are bound to become eclipsed, such as "science and culture" aspects (to what extent can we extrapolate "Western" principles to Asian contexts?) or "science and politics" aspects (the political pressures and expectations involved). South-Korea had invested significantly in Hwang's lab and demanded something in return, products that would boost the nation's international status. But this is not typical for East Asia. For similar reasons, President Clinton wanted to become associated with the costly and prestigious Human Genome Project by announcing (on June 26, 2000) its upcoming completion. Moreover, Hwang's research was really teamwork and one may wonder whether and to what extent Hwang himself (who invested significant amounts of time in activities such as touring and lecturing) was fully aware of what was actually going on in "his" laboratory. In order for such aspects to be addressed, a macro-ethical perspective is called for.

This paper consists of three parts. First of all, I will outline some of the changes that are taking place in scientific research worldwide, in terms of increase of scale, notably in areas such as genomics. More and more often, normative issues in science have to do with assembling and managing huge amounts of information. I will argue that this development calls for a different kind of research ethics than the basically "Kantian" micro-ethic that was developed during the second half of the Twentieth Century.
Subsequently, I will point out that the shift from a more or less principle-oriented approach, formulating obligations between individual agents (micro-ethics), to a more or less procedural approach, focusing on governance and transparency, on issues of organisation and institutionalisation (macro-ethics) is not without precedent. Basically, it is a "revival" (under modern conditions) of the tension between the ethical views of Kant and Hegel, between Moralität and Sittlichkeit. These dimensions of ethics are not in opposition to one another. Rather, they must be seen as complementary, more or less depending on each other. In the final sections, I will further elucidate the concept of macro-ethics by means of two examples, namely the use of animals in biomedical research and the ethics of databanking or biobanking. The basic claim of my paper will be that, although micro-ethics and macro-ethics are both important, we have to acknowledge that whereas research ethics on the micro-level is relatively well-advanced, macro-ethics still finds itself in a rather early stage of development. While we are relatively "fluent" when it comes to addressing issues such as autonomy and IC, our competences on the level of macro-bioethics are somewhat less developed. Bioethics is already moving in the direction of macro-ethics, putting more and more emphasis on ethics as an intrinsic part of science governance, and I will argue that we should encourage ourselves to proceed in this direction.

\section{Do "We" Have our Ethics In Place? The Issue of Scale}

While Gregor Mendel was an isolated researcher, without a formal research position or research grant (Orel 1996), and while the structure of DNA was uncovered by two scientists engrossed in an unofficial research quest, dropping out from their official research assignment more or less (Watson 1968/ 1996), contemporary research tends to be organised in the form of large-scale, multi-centre research endeavours, often involving hundreds of researchers and huge amounts of funding, bringing together experts from various fields and backgrounds. Whereas Mendel published a one-author article, and Watson and Crick's famous two-page publication (1953) involved only two authors, the Nature and Science publications that announced the completion of the 
"working draft" version of the human genome (IHGSC 2001, Venter et al. 2001) listed hundreds of "authors". This raises a question of a Foucauldian type: What does it mean to be an author in the genomics era? (Foucault 1994). ${ }^{3}$ Or, more generally: What does it mean to be a scientist, under contemporary conditions of pace and scale? To what extent is it still possible for individual researchers to constitute themselves as autonomous, responsible, decisionmaking agents?

An important dimension is of course the role of ICT. The computer has emerged as the generic research instrument, comparable to the book in Alexandrian and scholastic scholarship, quickly transforming virtually all research fields, not only in terms of contrivances for accurate measurement, data analysis and visualisation, but also in terms of communication and globalisation. An instrument originally designed as a powerful calculation machine was successfully transformed into a communication device (Licklider and Taylor 1968). Virtually all scientific disciplines of today have dramatically changed - in terms of their basic methodology, their technology, and even their epistemology-because of ICT. In the computer era, the key words are information and exchange. From a philosophical point of view, information is an intriguing phenomenon (Gaskell and Bauer 2006, 9 ff.; Thacker 2005). Because it is immaterial, it can migrate quite easily through electronic channels of communication. It can be managed, analysed and manipulated in various ways. Information is multi-functional and can acquire relevance and meaning in various contexts. Biomedical research has become very much an endeavour of producing, exchanging and interpreting information on an increasingly large scale. In many ways, the Human Genome Project (HGP) can be regarded as a paradigm for what is happening in the life sciences more broadly. It exemplifies not only the importance of scale, management and collaboration, but also of

\footnotetext{
$\overline{{ }^{3} \text { According }}$ to Foucault, authorship has fulfilled various functions in the course of history. In the scholastic era, it functioned as a quality mark or guarantee of truth ("Aristoteles dixit"). In the modern period, attribution of a particular finding to a particular author (through a formal publication in a scholarly journal) helped to solve priority conflicts. Nowadays, authorship has acquired new functions, for example in the context of retrieval or assessments of the performance of research groups.
}

electronic databases. On the ethical and legal level, the management of biomedical information raises complicated issues of ownership and responsibility, transparency and discretion.

Yet, while research in the life sciences is evolving into a large-scale, global, collective enterprise of bioinformation production and exchange, the traditional focus of life science ethics still tends to be on the responsibilities and duties of individual researchers (as autonomous agents) towards individual others that are physically present. And indeed, Western bioethics has become quite competent when it comes to addressing ethical issues on the micro-level $(N=1)$, where the focus is on respecting the autonomy of visible and tangible individuals (notably research subjects) in the context of one-to-one communications. Although this basic dimension of ethics will never become completely irrelevant, we cannot claim to have our ethics "in place" as long as we, as a complementary effort, over and above micro-ethical concerns, increase our competence to address novel issues emerging on the macro-level, issues that are an inherent part of research as a large-scale, global and collective enterprise, where $N=$ many and individuals as a rule will hardly become visible as individuals. Bioethics is shifting and has to shift its focus from the level of personal responsibilities in face-to-face interactions towards issues of bioinformation management, critically assessing the best practices evolving and the governance issues arisingin short, a more procedural type of ethics. Issues such as IC will not be regarded as unimportant on this level, but they will be reframed and readdressed. For instance, the question will not be whether or why IC is important per se, but rather how it can be realized and institutionalized, what best practices have emerged in various countries and contexts, and how they should be morally assessed? In other words, the focus shifts from an approach that basically addresses individual researchers as autonomous agents to an approach that looks at research communities as social networks embedded in political and cultural environments.

It would be a mistake to regard the increase in scale and pace, or more generally: the transformation of knowledge production that is currently evolving in the life sciences, a priori as a threat to ethics or even to humanity. Rather, the emergence of novel research practices, although they will challenge established moral frameworks no doubt, will also provide new opportunities for positioning and redefining ourselves 
as responsible moral subjects. Yet, increasingly, responsibility will become a collective effort that has to be consciously organised. Issues such as transparency, trust, professionalism and reliability will be key concepts in this domain. The same goes for issues involved in globalisation. Ethical quandaries will increasingly emerge against the backdrop of global collaboration and competition, and researchers will increasingly have to define themselves as moral subjects on an international scale. This also means that international institutions (such as UNESCO) will be expected to play an increasingly important role.

\section{Moralität versus Sittlichkeit}

An important point of departure for post World War II bioethics has been the philosophy of Immanuel Kant (1724-1804), who formulated the principle that we should act in such a way that we treat humanity, both in our own person and in the person of others, not as a means only, but always as an end in itself (1785/ 1903). The question is: how can we use someone (as a source of information, in the context of an experiment for instance) and still respect and acknowledge his or her autonomy as a moral person? The answer is: by asking (informed) consent. This principle became the cornerstone of research ethics and was built into countless codes of conduct both nationally and internationally. The focus, however, remains on scientist as responsible, individual agents, on the duties of individual researchers towards individual research subjects in the context of faceto-face interactions. The core issue in such an ethic is: respecting the autonomy of the immediate "other" (the research subject). The autonomy of this other must not be subordinated or sacrificed to the interests of other "others" (notably future patients). Other "others" are not completely absent from a microethical perspective, of course, and they may come into view through extrapolation, but the micro-situation remains the standard model. In a Kantian ethic, individuals remain abstract entities, rather than concrete individuals acting in concrete situations. Their consent as rational agents is what counts, not their biographies or institutional positioning. Kantian ethics envisions individuals in abstracto. Autonomy is an "assignment", moreover, rather than a privilege. Finally, in a Kantian perspective, autonomy means that we must dare to think for ourselves, to follow the imperatives of practical reason. It implies nonconformity: follow your own rational rules, rather than conforming yourself to collective strategies of behaviour.

Although this approach clearly has its strengths, it obviously has its weaknesses as well. Notably, it fails to see issues such as IC in a broader context (for example as a contrivance that facilitates research). ${ }^{4}$ It sees human individuals as theoretical entities rather than as concrete persons working in institutionalised environments, and therefore, a Kantian approach may not be very helpful when it comes to addressing the actual power issues, social factors and inequalities involved in research settings. Many debates over informed consent have to do with the "empirical" question, to what extent the consent given can really be regarded as voluntary (for example in the case of research with children, mentally retarded subjects, students or terminally ill patients)? For this, the social context, the broader working conditions have to be taken into account. Contemporary science is now adding some new concerns to these more "familiar" issues regarding individuals who may not be as autonomous as a Kantian ethics presupposes, such as: what should autonomy and IC amount to in research practices that take the form of global exchange of bioinformation and data-driven (rather than hypothesis-driven) research? How to address individual rights in the context of data-mining?

The awareness that autonomy, although important, does not in and of itself allow us to address concrete issues and actual problems emerging in real-life contexts is not new. On the contrary, one could say that this type of criticism was already formulated by Hegel (1770-1831) in the first decades of the nineteenth century (1821/1970). He argued that, although abstract normative principles directed towards guiding behaviour on the micro-level are important, we have to take the societal environment into account as well. Hegel referred to this as Sittlichkeit or "ethical life". On this level, the focus shifts from abstract principles (addressing individual subjects) to the ways in which these principles are realized or institutionalized. To frame it in contemporary terms: attention is now given to practices of

\footnotetext{
${ }^{4} \mathrm{Cf}$. the Hwang case: building an IC procedure into the trial becomes a technical ingredient in setting up a research design.
} 
application and implementation that are actually developing. In order for IC (for example) to work, we need a supportive ethical environment, a societal atmosphere in which such principles are regarded as important, not only by individual actors, but by large numbers of people. Society is then seen as a collective enterprise, where $N=$ many. Individual actors emerge as participants in complex networks that guide and facilitate (or discourage) certain types of behaviour. Conformity with existing practices and established lines of behaviour now becomes a positive feature. Ethics must focus its attention on these practices, the routines and guidelines they involve, by asking questions such as: how to implement normative principles and keep them up-to-date? This type of ethics will assess the functioning of ethical committees and of ethical expertise rather than analyzing the precise meaning of the word "autonomy". On the level of Sittlichkeit, ethics is not about face-to-face interactions, but rather about responsibilities of researchers in general towards large numbers of anonymous, invisible others. Hegel's view is not that Moralität is unimportant. Rather he insists that autonomy remains an abstract idea that somehow has to come to life, has to function in concrete settings on the macro-level, in the form of institutions and policies. ${ }^{5}$

Finally, macro-ethics allows us to loosen the association of ethics with anthropocentrism. Kantian ethics is basically about the duties of one particular moral subject towards another, where "moral subject" is identical to "human being", since (according to Kant and his followers) only humans are open to moral reasoning and susceptible to the voice of conscience. Macro-ethics, however, addresses the moral qualities of institutions, organizations and regulations, of research practices as such. Sustainability, for example, is a concept that is difficult to acknowledge within a Kantian framework, but from a macro-ethical perspective a normative assessment of research practices from the point of view of sustainability obviously makes sense.

\footnotetext{
${ }^{5}$ The book The imperative of responsibility by Hans Jonas $(1979 / 1984)$ may also be mentioned in this respect. Jonas argues that, whereas traditional ethics basically concerns itself with immediate and small-scale duties involved in interactions between individuals here and now, the new powers of science and technology force us to broaden the scale of our normative thinking in terms of time and space.
}

I am not claiming that macro-ethics is more important than micro-ethics. Rather, they must be seen as complementary dimensions. Sooner or later, issues such as IC, initially emerging in a microsetting, will have to be addressed on a macro-level as well. I am not suggesting that macro-ethics is inexistent. On the contrary, macro-ethical issues have received due attention in various contexts, but it is my conviction that the life science as they are evolving today entail new challenges that will predominantly have to be addressed in macro-terms. Historically speaking, research ethics (notably the ethics of biomedical research) originated in the context of experimentation with human subjects. Worldwide rejection of the use of prisoners during World War II greatly reinforced general awareness of the pivotal importance of IC. The (macro-ethical) question how to institutionalise biomedical research ethics has always been on the agenda as well. The post-war resurgence of ethics resulted in the establishment of bioethics committees as a basic tool for safeguarding autonomy. Issues such as the meaning and status of ethical expertise or questions concerning the role of ethics committees-for instance, should consensus formation be regarded a viable objective? (Ten Have and Sass 1998)-have been thoroughly debated. Procedures for ethical assessment became an inherent part of research activities. Still, the starting point remained the Kantian question "What ought I to do?" and the emphasis was on the autonomy of individuals who participated in research trials. The way biomedical and biological research is now evolving, however, forces us to broaden our perspective. I will elucidate this by means of two examples.

\section{A First Exemplification: Animals in Biomedical Research}

The discussion over the use of (vertebrate) animals in biomedical research may stand as a first "problem file" to exemplify the shift indicated above. Until recently, the focus in this debate was on basic ethical concerns, such as animal suffering, animal rights, the integrity of animals and intrinsic value. Participants in ethical debate tried to convince one another that animals have (or do not have) basic rights, that they have (or do not have) intrinsic value, that they should (or should not) be regarded as subjects of experience, 
etcetera. On a theoretical level, advocates of utilitarianism for example would argue that the amount of suffering is all-important while Kantians would argue that only those entities can have rights that may acknowledge the rights of others (and this apparently only applies to humans). On a more practical level, the issue of how to balance animal suffering against the interests of future patients was addressed on the level of basic considerations that somehow had to be traded-off against one another.

In recent years, however, the emphasis has shifted quite unequivocally to a different set of issues, a different type of questions, of a much more procedural nature. Moral deliberations and concerns nowadays tend to focus on the adequacy, efficiency and transparency of the assessment process of animal research as it is carried out by animal ethics committees and other institutionalised bodies. What kinds of expertise should be represented in such committees? What should be their role and, above all, how transparent should the process be? To what extent should commissions share their input, their considerations and their output with the outside world? How confidential is the information handled by those involved? In other words, the focus has moved from basic principles and concepts to procedural issues and to the moral quandaries involved in the management of "sensitive" bioinformation.

One important procedural issue is representation. Can we leave the decision making to the expert committees, or should the public be involved, or at least informed, and how should this be organised? Should it be made public for instance how many animals are used and for what purposes? Or would such a policy conflict with concerns of confidentiality when dealing with vulnerable intellectual property such as research proposals? Who exactly is responsible for making decisions in this domain (researchers, committees, institutes?) and how are these decisions made? In other words, how is the process of moral deliberation institutionalised and organised? What best practices have evolved in various countries? Is global harmonisation or research regulation possible? To what extent can experts involved in this process be trusted by the public? Who are they representing?

These are normative issues, no doubt, but they approach the issues at hand from a different angle. Moreover, animal research has become an international and even global endeavour. Strict regulations on the national level may not reduce the amount of animals used for research, nor the suffering to which they are exposed, but may rather stimulate the migration of research activities to other geographical areas where regulations are less severe, or to competing research networks (unless harmonisation can be established, for example on the European level). Research with animals basically produces information, and this implies that the actual site where the research is conducted is of relative importance. Information can be exchanged, in the context of global networks, and the actual work with animals may migrate to countries where legal constraints are relatively mild. One could say that, to the extent that research has become a global affair, research ethics has to become a global affair as well, in order to remain effective. Thus, the focus of concern has shifted from debates over the value and status of living entities to debates over the management of information. The latter includes issues such as transparency, accessibility, reliability and confidentiality.

\section{Biomedical Research in the Bioinformation Era}

My second example concerns the use of bioinformation (notably genetic information) in research. As was indicated above, the focus of biomedical research practices is changing. Globalisation, "informatisation" and the increase of scale are omnipresent features of contemporary bioscience. Besides trials involving visible and tangible research subjects (patients, students or others), another source of information is becoming increasingly important, namely databases containing bioinformation provided by anonymous (and often healthy) individuals. A biobank is a source of data for researchers, physicians, patients and others and exemplifies the growing importance of bioinformation in research and health care. It can be defined as an interface between individuals (patients or healthy individuals) providing data or bodily materials on the one hand, and biomedical researchers using these data and materials on the other. Professionals involved in biobanking have the obligation to provide high quality, accurate data, while at the same time respecting the rights of privacy and confidentiality of the providers. The growing importance of biobanking implies a dramatic change for research ethics, a shift of focus from practices involving interactions be- 
tween visible individuals to novel practices consisting in the management and interpretation of information, notably genetic information, where individuals usually remain invisible.

This change has been clearly outlined by Collins (1999) in a famous article in which he presents the HGP as exemplifying an ongoing paradigm shift in medicine and biology: the dawning of the information era. According to Collins, the HGP is basically an effort to sequence our genetic code, making the information available to research communities worldwide through a public repository (GenBank, www. ncbi.nlm.nih.gov). According to Collins, genomics changes the way in which biomedical and biological research is done. Research subjects or patients as embodied individuals are no longer the main target of this type of research. Rather, genomics is directed towards producing, using and interpreting (genetic and other forms of) bioinformation. This has consequences for ethical or societal research as well. In the context of the HGP, the use and interpretation of information was identified as the first high priority area for ELSI (ethical, legal, social issues) research (Collins 1999, 34). In Collins' vision, future individuals will (on the basis of interactive electronic IC procedures) increasingly use genetic tests based on knowledge retrieved from large-size databases before making important decisions (such as career choice). ${ }^{6}$ Thus, in the "genomics" or "bioinformation" era, the focus of biomedical research will shift towards novel practices based on using and interpreting information provided by large populations.

It is no coincidence, therefore, that a growing part of the bioethical literature is devoted to issues involved in genetic databases and biobanking. The traditional biomedical and bioethical situation (the encounter between researcher and research subject) is complemented (and to a certain extent eclipsed) by a novel situation in which large numbers of (often healthy) individuals provide information to databases.

\footnotetext{
${ }^{6}$ A similar position was taken by Collins' competitor Craig Venter, who characterized the research facility Celera he set up as "an information company" (Shreeve, 120), a source of genomic information on a global scale, a massive database that could be consulted by researchers, but also by individuals who wanted to govern their own health condition on the basis of genomic information. Indeed, Celera's formal mission statement was to become the "definitive source of genomic information" worldwide.
}

In the traditional encounter, the Kantian "What ought I to do?" was answered in terms of the categorical imperative demanding professionals to treat humanity, represented by this one tangible, visible individual, as an end in itself. Biobanking, however, exemplifies research under different conditions, on a much larger scale, involving completely different kinds of interaction between researchers and research subjects, mediated by electronic devices. Individuals are basically providers of data. In principle, they remain anonymous and invisible. Indeed, while their information continues to be stored, managed and processed in electronic libraries, they themselves may no longer be alive. Communication is virtual and digital. Discrete human beings are replaced by stored information as the object of data-driven research. In order to adequately address the ethical issues involved in such practices, we need a biomedical research ethics for collective enterprises devoted to management of sensitive bioinformation on a large scale. The fact that scientific research has become a complex, technology-dependent enterprise may increasingly outdate the focus of traditional bioethics on individual duties towards the discrete moral subjects we are facing. The shift in focus from individuals $(\mathrm{N}=1)$ to populations $(N=$ many) and from encounters with individuals who are physically present to exchange of bioinformation calls for a different approach.

The conviction that the emergence of biobanking implies new challenges for bioethics is clearly addressed by Knoppers and Chadwick (2005). Population-based genetic research, they claim, has led to calls for rethinking the paramount position of the individual in ethics. Whereas individual-oriented ethics will place much emphasis on principles such as IC, in the new situation other issues become important, such as solidarity and trust.

This explains why notably in ethical debates over biobanking and genetic databanking authors are moving beyond the more or less traditional agenda of bioethics. According to Williams (2005), our "dominant focus on individual rights [is] ill-suited" when it comes to reflecting on issues involved in large scale collaborative research (51). The most important dimension that the IC language fails to address, he claims, is that of power. Individuals are confronted with large-scale, highly professional organizations functioning in electronic environments. An IC procedure will not allow us to address the 
moral quandaries emerging in such a situation: "requiring consent will not, by itself, alter the fact that uncoordinated individuals are always subject to the power of organised groups or institutions" (53). Indeed, a focus on individual rights may even "hinder us in appreciating the ethical issues that large-scale biobanks raise" (51). Important social, political and scientific questions are left out of consideration.

Apparently, there is a growing conviction that biobanks and bioinformatics databases introduce new types of conflict and tension that cannot be addressed in terms of the traditional bioethical toolbox. One of these conflicts is that between the scientific ideal of free access to detailed, up-to-date bioinformatics databases (an important methodological condition, but an ethical ideal as well) and the traditional ideal of informed individual autonomy (Bovenberg 2005). In order to "harvest" the new potentials for life-sciences, researchers will often want to make use of databases in a much more flexible manner, in various contexts and for various purposes. Yet IC procedures set limits to the use of biobank information (Bovenberg 2005). In order to articulate the interests of individuals who act as sources of information, other ethical tools and concepts, such as benefit sharing or engagement in agenda-setting for research, may become much more important than IC. In other words, the management of biomedical information generates new questions concerning accessibility of information, priority setting and fairness. Individuals, patient organizations, even the public at large may well become more interested in co-developing the agenda for research than in the legal intricacies of IC. Similar to the shift towards procedural issues in animal ethics such as transparency, there is a growing interest in the biomedical field in moving away from the traditional ethics expert committee model (applying micro-level principles to cases and research applications) towards developing methods to involve much broader audiences in moral deliberations, through panels, surveys, discussion forums and other ways of consulting and involving "publics". This again reflects the desire to move away from the traditional IC issues towards broader ones such as: for what purposes (or even: for which research programs) do we as a society find the use of animals in research legitimate?

All this implies that bioethicists should be more interested in the collective responsibilities of research communities engaged in exchanging and interpreting bioinformation than in the personal (immediate) duties of researchers on the micro-level. Research ethics has become part of science governance as a comprehensive approach in which privacy regulations constitute only one element among various other considerations. Issues involved in institutionalisation at various levels (the role of ethics committees and of various forms of expertise, the process of quality control, priority setting and funding policies, regulations for managing electronic databases) will increasingly determine the bioethical agenda. Besides IC, other normative concepts (free access, transparency, benefit sharing, open source IP policies, public engagement) will gain importance. And as far as IC is concerned, the focus will be on how it is to be organized, maintained and balanced against other important normative issues.

Moreover, IC procedures must not be seen as evolving in a moral vacuum. Rather, they presuppose a supportive moral culture or climate - a "moral life" as Hegel phrased it. IC remains an abstract issue as long as the legitimacy and trustworthiness of institutions involved in research practices (locally as well as globally) are left out of consideration. This is also a basic lesson from the Hwang case. In a world of global competition and collaboration it becomes increasingly important to ensure that standards of oversight in laboratories worldwide are sufficiently adequate for making the Hwang scenario increasingly "improbable" (Nature 439, 117). This calls for transnational institutions, moral "players" in the global field of science ethics.

One of the candidate institutions for playing such a role is UNESCO, author of documents like The Human Genome and Human Rights and Declaration of human norms in bioethics and Code of Conducts for Scientists, but this is a contentious issue. First of all, in many respects these UNESCO documents are still addressing researchers from a classical (microethical) perspective, as autonomous individual agents. They do not really enable research communities to manage the moral quandaries that are emerging in contemporary science as a large-scale, global enterprise. They build on established ethical principles, rather than on a solid analysis of how life science research is actually evolving within society. Moreover, in the editorial to a special issue of Developing World Bioethics, the latter UNESCO declaration has been fiercely criticized (Landman and Schüklenk 
2007). It was argued that the concepts used in this document were too general and vague to generate real commitment and, moreover, that UNESCO was not supposed to issue such declarations at all. According to the authors, bioethics should be left to the bioethicists. Although I do not find the arguments used for criticising this document very convincing (Zwart 2007), the debate as such indicates that the development of a global macro-ethics still finds itself in an early, "prenormal" stage. Moreover, organisations such as UNESCO are just as much a product of global forces as are researchers and their organisations. So far, national institutions play a much more prominent role in safeguarding the ethical standards for research than international bodies.

Open Access This article is distributed under the terms of the Creative Commons Attribution Noncommercial License which permits any noncommercial use, distribution, and reproduction in any medium, provided the original author(s) and source are credited.

\section{References}

Bovenberg, Jasper A. 2005. Blood, sweat and grants. 'Honest Jim' and the European database right. Genomics, Society and Policy 1: 1-28.

Collins, Francis. 1999. Medical and societal consequences of the Human Genome Project. New England Journal of Medicine 341: 28-37.

Dickenson, Donna L. 2007. Property in the body: Feminist perspectives. Cambridge: Cambridge University Press.

Foucault, Michel. 1994. Qu'est-ce qu'un auteur? In Foucault M. Dits et Écrits I, 789-809. Paris: Gallimard.

Gaskell, George, and Martin Bauer. 2006. Genomics and society: Legal, ethical and social dimensions. London: Earthscan.
Gottweis, Herbert, and Triendl Robert. 2006. South-Korean policy failure and the Hwang debacle. Nature Biotechnology 24: 141-143.

Have Henk ten, Sass, Hans-Martin. eds. 1998. Consensus formation in healthcare ethics. Dordrecht: Kluwer.

Hegel Georg Wilhelm Friedrich. 1821/1970. Grundlinien der Philosophie des Rechts [Philosophy of Right]. Werke in zwanzig Bände 7. Frankfurt: Suhrkamp.

Hwang Woo-Suk, et al. 2004. Evidence of a pluripotent human embryonic stem cell line derived from a cloned blastocyst. Science 303: 1669-1674.

International Human Genome Sequencing Consortium. 2001. Initial sequencing and analysis of the human genome. Nature 405: 860-921.

Jonas, Hans. 1979/1984. Das Prinzip Verantwortung. Versuch einer Ethik für die technologische Zivilisation [The imperative of responsibility: in search of an ethics for the technological age]. Frankfurt: Suhrkamp.

Kant, Immanuel. 1785/1903. Grundlegung zur Metaphysik der Sitten [Groundwork for the Metaphysics of Morals]. Gesammelte Schriften. Band IV pp. 428-434. Berlin: Akademie Ausgabe.

Kennedy, Donald. 2006. Editorial retraction. Science 311: 335.

Knoppers, Bartha, and Ruth Chadwick. 2005. Human genetic research: emerging trends in ethics. Nature Reviews Genetics 6: 75-79.

Landman, Willem, and Udo Schüklenk. 2007. Editorial. Developing World Bioethics 5(3): iii-vi.

Licklider, J, and Robert Taylor. 1968. The computer as a communication device. Science \& Technology 76: 21-31.

Orel, Vitizslav. 1996. Gregor Mendel. The first geneticist. Oxford: Oxford University Press.

Thacker, Eugene. 2005. The global genome. Biotechnology, politics and culture. Cambridge: MIT Press.

Venter J Craig et al. 2001. The sequence of the human genome. Science 291: 1304-1351.

Watson, James D. 1968/1996. The double helix. A personal account of the discovery of the structure of DNA. New York: Simon \& Schuster.

Williams, Garrath. 2005. Bioethics and large-scale biobanking: individualistic ethics and collective projects. Genomics, Society \& Policy 1: 50-66.

Zwart, Hub. 2007. Statements, declarations and the problem of ethical expertise [Editorial]. Genomics, Society \& Policy 3 (1): ii-iv. 